This item was submitted to Loughborough's Research Repository by the author.

Items in Figshare are protected by copyright, with all rights reserved, unless otherwise indicated.

\title{
Older users' requirements for interactive television
}

PLEASE CITE THE PUBLISHED VERSION

PUBLISHER

(C) Springer

LICENCE

CC BY-NC-ND 4.0

\section{REPOSITORY RECORD}

Boyle, H., C.A. Nicolle, Martin Maguire, and Val Mitchell. 2019. "Older Users' Requirements for Interactive Television". figshare. https://hdl.handle.net/2134/3006. 
This item was submitted to Loughborough's Institutional Repository by the author and is made available under the following Creative Commons Licence conditions.

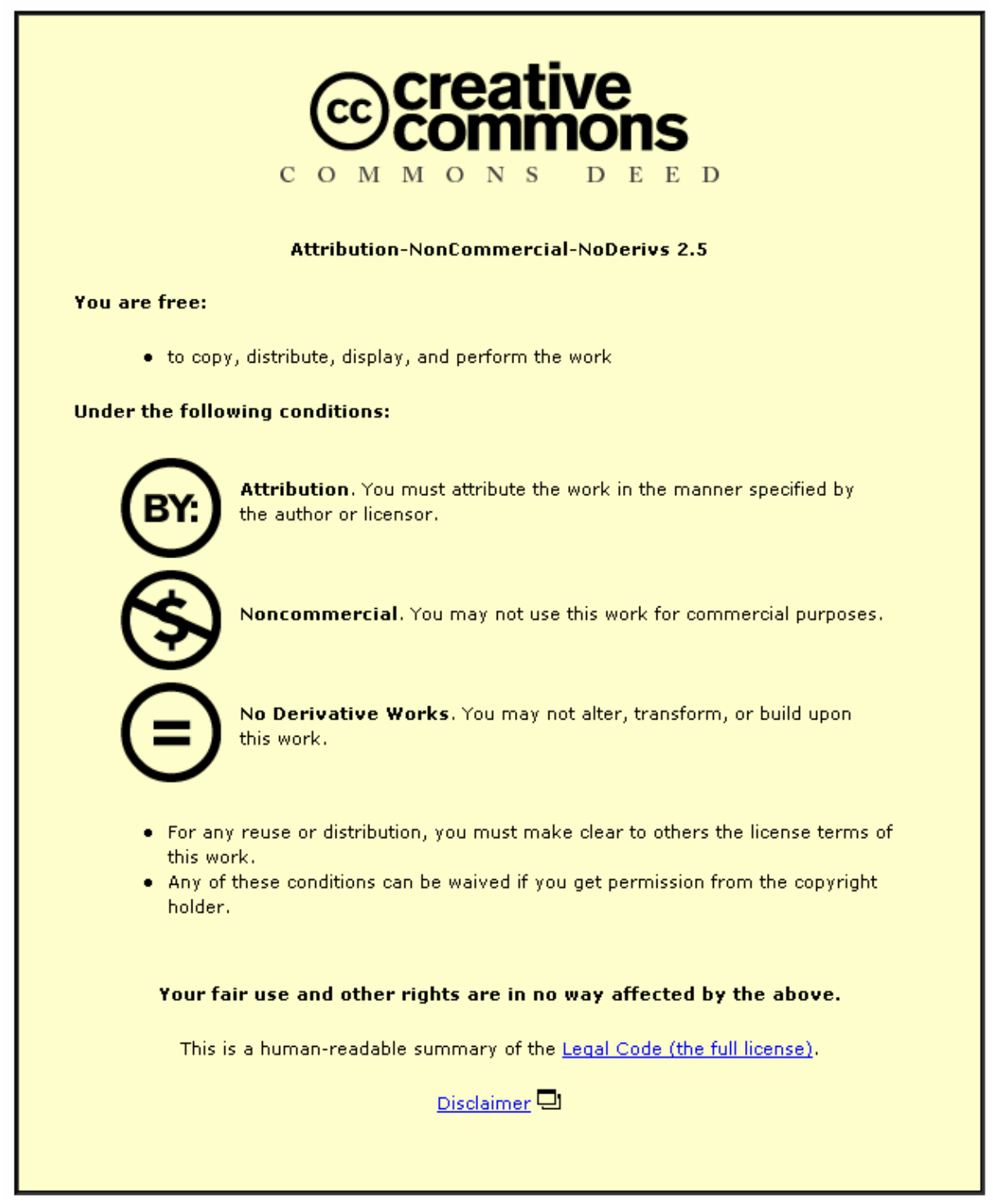

For the full text of this licence, please go to: http://creativecommons.org/licenses/by-nc-nd/2.5/ 


\title{
Chapter 9
}

\section{Older Users' Requirements for Interactive Television}

\author{
H. Boyle, C. Nicolle, M. Maguire, and V. Mitchell
}

\subsection{Introduction}

In Britain some $62 \%$ of households have access to digital television, and the British government has mapped out a plan to steadily shut down all analogue TV signals by 2012 (Lowery Miller 2005), with the expectation that all UK households will benefit from the digital future. Over the next few years, television and the Internet are expected to converge even more so to create a communication and information medium for the mass market, enabling on-line access without needing to purchase and learn the intricacies of computers.

With digital technology being actively encouraged by the Government, how can iTV in the future be designed to improve the lives of older people? And which services will be of particular benefit to them? Older people often have a combination of impairments such as poor hearing/vision, reduced mobility/ dexterity, and may have reduced cognitive ability. Zajicek (2001) states that the ageing process affects an individual's ability to function successfully with the standard graphical user interface and that the capabilities required for interaction with an interface are the ones that deteriorate most markedly with age. However, older people are generally willing to use computers and find the experience a satisfying one. Older computer users are an important group to ascertain if there is an interest in the uptake of iTV. But equally, is there the same interest in uptake by older non-computer users? Most importantly, what are the user requirements from both computer and non-computer older users to provide an inclusive iTV service?

Keates \& Clarkson (2004) identified specific causes for concern with regard to interaction with digital television (DTV) with the use of a set top box (STB). The majority of their sample age ranged from 62-85 years old, and they found that for this population there was a high cognitive, visual and dexterity demand on the participants to use the DTV. They recommended to manufacturers that cognitive demand should be kept to a minimum and the interaction with the STBs should be as transparent as possible. This, they advocate, is not aimed just at a small section of the market, but instead is good design for everyone. 
Organisations that are promoting iTV should consider older users' requirements to aid in maximum independence, both in their usage of the system and activities of daily living. To make this happen, there must be sufficient interest and action from service providers to promote the inclusive design concept. This study is therefore a step forward in attempting to identify what older users' requirements are for the future of inclusive iTV.

\subsection{Background}

This study was undertaken in part-fulfilment of the requirements for the postgraduate course in Ergonomics at Loughborough University. The objective was to evaluate what older users' requirements are for iTV, including the services that they would value (e.g., e-mail or the World Wide Web), and explore barriers (e.g., technology complexity, usability, etc.). This was part of a larger project, the Services Aggregation Project (SA), part of The Application Home Initiative (TAHI at http://www.theapplicationhome.com), undertaken at the Ergonomics and Safety Research Institute and sponsored by the Department of Trade and Industry. Under the auspices of Severn Trent Water and with the support of Leicester City Council, an energy and water efficiency monitoring trial (called SMART) was installed within a number of homes in Leicestershire as a pilot study. The trial was developed to build upon an Automatic Meter Reading System, which would feed a server-based system, an XTN hub from Extrada, which would then aggregate the metering data with water and energy saving advice and other services, to provide an aggregated services set. The trial utilised Digital TV set top boxes in each trial home, enabling both email and web browsing, whilst at the same time being able to view the current TV programme in the top right-hand corner ('picture in picture' or PIP). To augment this service and to encourage the user to look at the water and energy consumption data, a number of other services were also provided, including saving advice, home shopping, entertainment and meal planning (see Figure 9.1). These services had been re-purposed for TV format and accessible from an Internet portal via the TV and digital Netgem box.

Overall the TAHI SA project had 3 objectives:

- to test user reactions to the SMART set of services;

- $\quad$ to test the usability of the services and learn lessons for future design;

- to study user acceptance of the idea of receiving services through a TV (as opposed to a PC).

In addition, the project was interested in targeting structured groups of older users to assist in formulating and promoting future iTV applications. As older people are the fastest growing sector in the world's population, the issue of accessibility and usability of these products and services has become critical. Since a very large percentage of the television audience, especially during the daytime and non-peak viewing hours, is made up of disabled and elderly people (Gill 2004), it is clear that service providers should give more thought to providing more inclusive access. 


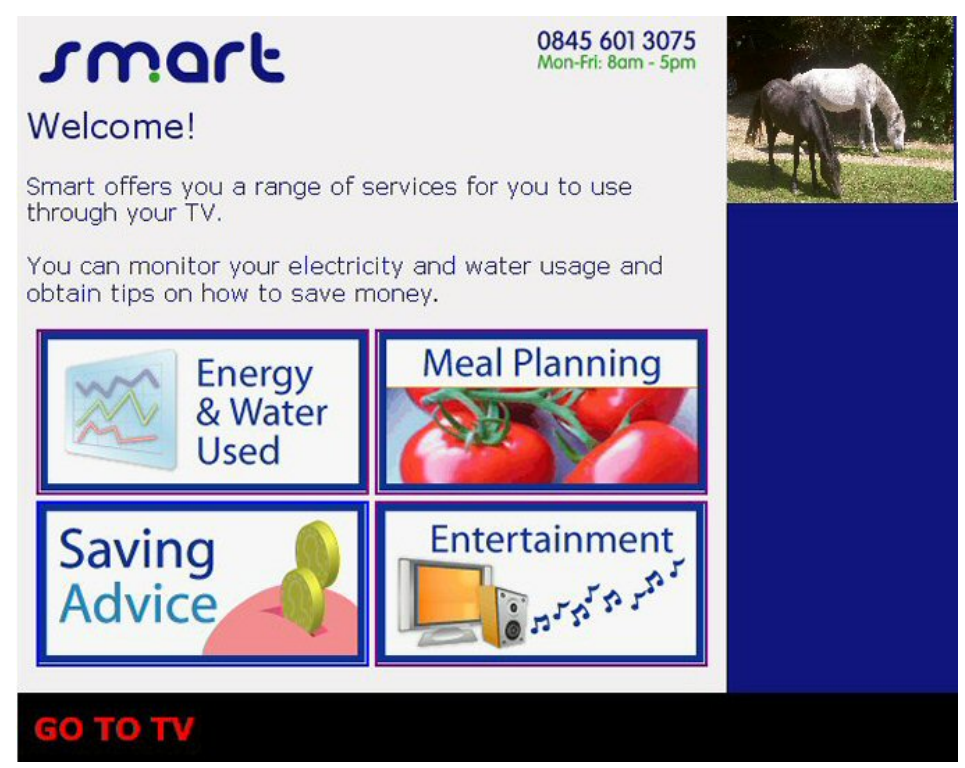

Figure 9.1. SMART home page

This is where the current study began, and where the University of the Third Age (U3A) came on board (although we have to say that our users from U3A were certainly not the 'stay at home' type!). Although the usability of iTV in this specific part of the project was not under investigation (for the usability assessment see Maguire, Mitchell and Nicolle, 2005), it was also essential to assess its usability to some extent in order to understand the older users' requirements. The focus therefore was to:

- identify user requirements for iTV services concerning older users;

- $\quad$ address concerns/barriers that would need to be overcome;

- formulate recommendations for future successful implementation of iTV in older users' homes.

\subsection{Methodology}

Data collection of user requirements involved qualitative research methods over two phases. The first phase consisted of three focus groups with a total of twenty participants, taking place in June 2005. This method was chosen because focus groups offered an efficient way to provide qualitative user feedback on the Interactive TV services being considered. Although a survey could have been conducted with a wider range of people, it was felt that this would not produce the 
same richness of data and allow users to refine their views in discussion with others. The groups were made up of computer and non-computer users from local groups of the University of the Third Age. A married couple from the U3A offered their home for the first focus group and the user trials, in order to provide a realistic environment to maximise the potential of iTV. SMART was installed in their home, including the energy and water usage monitoring system, but due to budget constraints STBs could not be offered to all participants, at least at this stage. The other two focus groups were held at ESRI.

The basic procedure was as follows: For each group, the iTV and the SMART system were demonstrated. The users were then asked to discuss their initial requirements, concerns and issues related to the service. A concept board was then introduced to generate new concepts and ideas on iTV. The participants were encouraged to select pictures from a range provided and then to choose an image that would represent facilities they would like to see on iTV. Using a word map, participants were also asked to provide a word or sentence on their concerns or issues, and these were placed on a flip chart to prompt further discussion.

The second phase of the study involved user trials with eight participants from the first focus group. Performing user-based testing allowed the users to experience the TV services and rate their usefulness while also indicating to the evaluator how usable the services were. The aims of the user trials were:

- to reinforce the function of the iTV;

- to allow the participants to experience iTV;

- to explore the findings from the focus group even further in order to highlight the key user requirements, concerns/barriers/issues, etc.;

- to identify if there are any differences between computer/non-computer users;

- to rate the equipment and services on an individual basis;

- to identify participants' impairments further to ascertain if there are any problems interacting with the iTV.

The participants carried out a pre-defined set of usage scenarios using the iTV. The tasks given to the users involved: viewing and interpreting energy and water usage charts on the TV screen, planning a meal with certain ingredients using the Cheffy meal planning tool, identifying energy and water saving tips, finding famous quotes online, performing a Google search, and sending an email using the digital TV email service.

User interface issues and user ratings of the different services were recorded. These tasks were followed by a semi-structured interview to provide further detailed information on user requirements. User ratings of the services indicated that the most popular were TV-based Internet and email, as well as advice on saving energy and water.

One might question whether older people from U3A are representative of the older population in general. The background of these participants ranged from lecturers, teachers, doctors, engineers, etc., coming from similar socio-economic backgrounds, and hence their views may differ from those of other older people. In addition 15 out of 20 of them were computer users. However, the sample can be 
justified as the service provider sought to target structured groups of older people such as the U3A to use as a platform, i.e., it has transfer potential. Further trials are, however, recommended to cover a wider range of older users from different educational and social groups. The sample for both the focus groups and user trials is provided in Tables 9.1 and 9.2 below:

Table 9.1. Focus groups sample (total 20)

\begin{tabular}{|lr|lr|lr|}
\hline Gender & Age & Computer Usage & \\
\hline Males & 8 & $80-89$ yrs & 2 & Computer users & 15 \\
\hline Females & 12 & $70-79$ yrs & 16 & Non-computer users & 5 \\
\hline & $60-69$ yrs & 2 & & \\
\hline
\end{tabular}

Table 9.2. User trials sample (total 8)

\begin{tabular}{|ll|l|ll|}
\hline Gender & Age & Computer Usage & \\
\hline Males & 4 & Ranged from 73 to 86 & Computer users & 4 \\
\hline Females & 4 & & Non-computer users & 4 \\
\hline
\end{tabular}

\subsection{Analysis and Results}

\subsubsection{Main Themes of User Requirements}

A thematic approach to data analysis was used including three steps: data reduction, data display and conclusion drawing/verification (Hignett, 2004). The data from both the focus groups and user trials were transcribed and imported into a qualitative data management tool, Nvivo (http://www.qsrinternational.com/). The data were summarised and coded to identify key themes and their sub-categories, and memos, quotes, and references were linked to codes where relevant.

Emergent patterns were selected based on how many times a specific point was mentioned in the data. 14 main themes were identified, with codes being added, removed or relocated to reflect additional data and iterative analysis. Each main theme was then decomposed, in both diagrammatic and tabular form, into its subcodes. 6 of these main themes are headings for the services provided by SMART (e.g., energy and usage, saving tips, etc.), with the users rating those services. The remaining 8 (requirements, concerns, impairments, iTV, computers, equipment, U3A, e-mail) are the themes that were identified from the conceptual framework of knowledge and thoughts at the start of a project. It is important to note, however, that although user requirements had a separate heading within Nvivo, specific requirements overlapped with the other themes. The 14 key themes/trees from the data collection were then systematically re-coded in order to identify prominent 
patterns, which were then used as a framework to investigate all the results from the focus groups and user trials (see the data display in Figure 9.2).

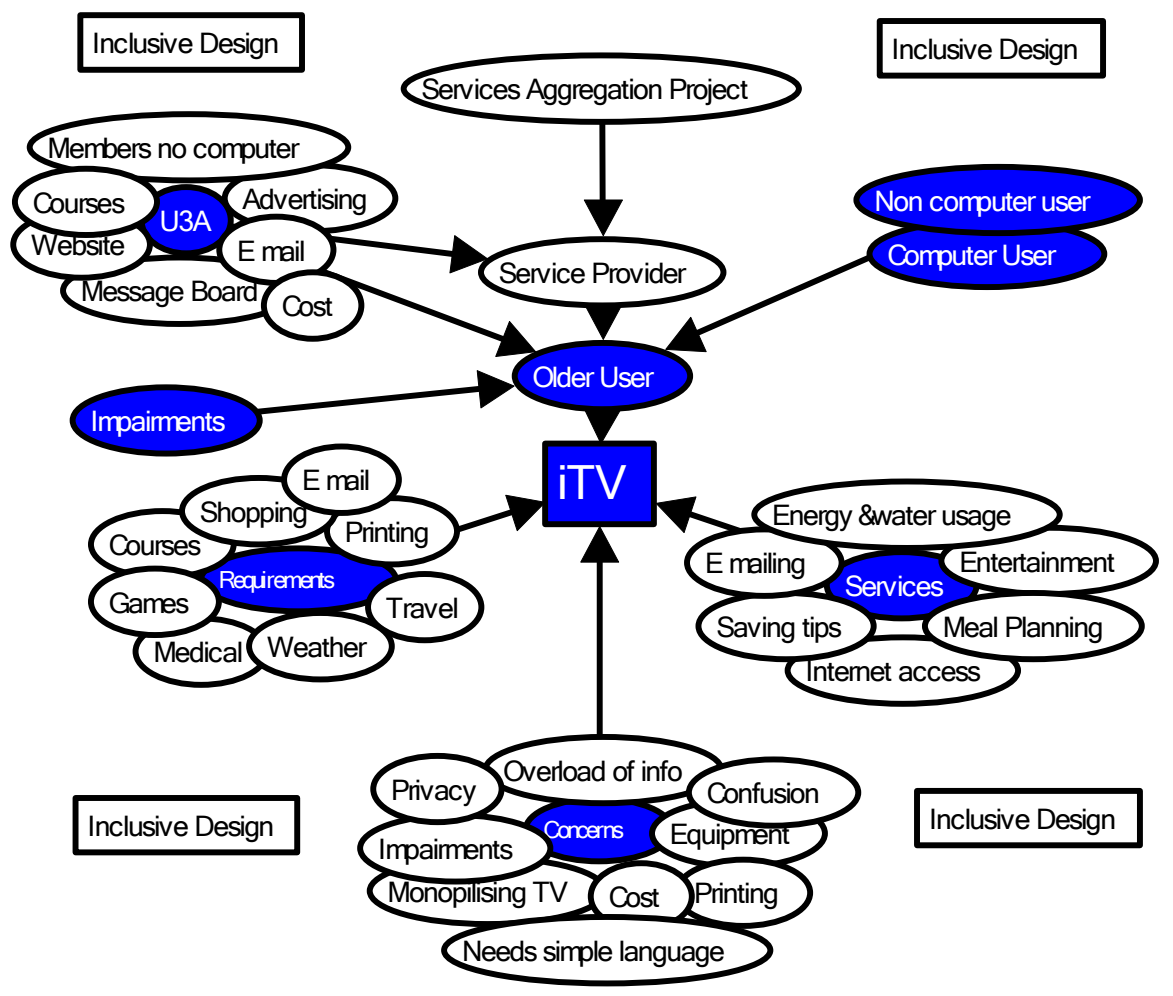

Figure 9.2. Data display as a framework for analysis

\subsection{2 iTV Concerns}

To illustrate with just one example from the main themes, there were 28 sub-codes in total under the theme 'Concerns,' from which 9 key concerns were extracted (see bottom of Figure 9.2). These highlighted the main issues or barriers that older users may have: overload of information (TV was for relaxation and not for looking up information), privacy (if other family members are present when using email), confusion (iTV offers more functionality and thus requires more cognitive effort to learn and operate than ordinary TV), equipment (some usability issues with the remote control and the need for wrist support when using the keyboard on one’s lap), printing (facility not available), monopolising the TV (when others may 
wish to watch it), cost (of the STB, broadband, and services), impairments (e.g., difficulties manipulating the remote control due to arthritis, and difficulties to scan the TV and read the keyboard when wearing varifocals or separate glasses for reading and distance), and the need for simple language.

Since the sample of users was relatively well educated and articulate (U3A), with a large proportion having computer experience, it is likely that many of these concerns would be amplified for many other older people. These themes provide useful context for the design of iTV services in the future.

\subsection{Conclusions and Recommendations}

In summary, this study found that computer users and non-computer users were positive about iTV. However, computer users were a bit more apprehensive due to the lack of privacy, printing, sending of attachments and access to Word, etc., but this did not seem to be an issue with non-computer users. A number of impairments (including difficulties with vision, hearing and dexterity) limited access to the iTV when using the keyboard or remote control and when viewing the interface. Concerns and barriers need to be addressed to accommodate older users' requirements. Cost, overload of information, confusion regarding the technology, the need for simple navigation/language, and the design of the remote control and keyboard for iTV use are all such areas that need to be targeted. It seems that this group of older users would be willing to use the iTV in the future if (1) the benefits are clear to them, (2) they receive adequate instruction, and (3) the system itself is easy to use.

The project has made a number of recommendations to ensure a more inclusive design of iTV, which will meet older users' requirements, for example:

- in order to accommodate users with visual impairments and limited dexterity, ensure that relevant design guidelines are adhered to (e.g., from CENELEC at www.cenelec.org/Cenelec/Homepage.htm, the BBC at www.bbc.co.uk/commissioning/bbci/pdf/styleguide2_1.pdf, the RNIB and COST 219ter at www.tiresias.org/cost219ter/about.htm and http://www.tiresias.org/guidelines/television.htm);

- to reduce wrist, back or neck strain, consider innovative hardware design solutions, e.g., a keyboard offering more stability and comfort on the lap, perhaps with a gel/sponge base;

- install the set top box at an appropriate height to allow for ease of access (3 out of the 8 in the user trials had problems with their knees and hips);

- to reduce overload of information, consider personalised information services for specific users or groups of users;

- provide the ability to communicate with other key people in the community, e.g. doctors, nurses, advisors, and any other service they require;

- provide the facility to send attachments, print and access Word;

- enhance communication and entertainment services; 
- enable customisation of the interface design (layout, text size, contrast, etc.);

- promote and facilitate the re-purposing of websites and services for iTV viewing;

- incorporate a help line into the service provision to reduce anxiety, especially by older users. Although TV digital services such as Freeview do not normally provide such help, this might be an opportunity for digibox manufacturers to make their products more attractive. Electrical stores competing on the high street are also realising the benefit of providing more technical help to customers;

- provide a clear breakdown of costs, e.g., broadband, equipment, services, support, etc., which is paramount in attracting older users.

This study suggests that, for the time being for older users, the main focus for iTV applications should be on entertainment and simple communication. The common need for entertainment is the predominant driving force behind the traditional TV, and interactivity seems to be foreign to the traditional use of TV by at least some older users. As one participant mentioned, she does not want to be bombarded with information when sitting in front of a TV - she is in the mode of escaping and relaxing. However, this may change with the next older generation, who will be used to information "on tap" through multi-modal interaction devices. This project has covered only a small sample of older users and highlighted certain requirements and issues. In order to ascertain a global overview of older people's requirements, a more lengthy study is required, including a wider range of older users with different backgrounds and experiences in the use of technology.

\subsection{References}

Gill J (2004) Inclusive Design of Interactive Television at http://www.tiresias.org/reports/dtg.htm

Hignett S (2004) Qualitative Methodology. In Wilson JR and Corlett N (eds.) Evaluation of Human Work, $3^{\text {rd }}$ edn., Taylor \& Francis, London, pp 113-128

Keates S and Clarkson J (2004) Assessing the Accessibility of Digital Television Set-Top Boxes. In Keates S, Clarkson J, Langdon P, and Robinson P (eds.) Designing a More Inclusive World, Springer, London, pp 183-192

Lowery Miller K (2005) The Airwaves Go Digital, Newsweek, 6-13 June, pp 59-63

Maguire M, Mitchell V and Nicolle C (2005) TAHI Services Aggregation Project, SMART Service Development and User Trial. Ergonomics and Safety Research Institute, Loughborough University

Zajicek M (2001) Supporting Older Adults at the Interface. In Proceedings of Interact 2001, Eighth IFIP TC.13 Conference on Human-Computer Interaction, 9-13 July, Tokyo, Japan, IOS Press, pp 447-454 